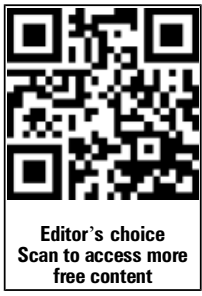

- Some references are published online only. To view them please visit the journal online (http://dx. doi.org/10.1136/archdischild2012-303078)

${ }^{1}$ Nottingham University, Derbyshire Children's Hospital, Derby, UK

${ }^{2}$ Department of Paediatrics, Birmingham Children's Hospital, Birmingham, UK

\section{Correspondence to} Dr Will Carroll, Nottingham University, Derbyshire Children's Hospital, Uttoxeter Road, Derby DE22 3NE, UK; will.carroll@nhs.net

Received 24 September 2012 Revised 15 February 2013 Accepted 26 February 2013

Published Online First

9 April 2013
To cite: Carroll WD,

Srinivas J. Arch Dis Child Educ

Pract Ed 2013:98:113-118.

\title{
Bronchodilators in wheezy under 2-year-olds: when and which (if any)?
}

\author{
Will D Carroll, ${ }^{1}$ Jyothi Srinivas ${ }^{2}$
}

\section{CLINICAL CASE}

Amy is 13 months old and presented to the children's emergency department with a 5-week history of wheezing. Her parents explain that they have seen her general practitioner twice and attended the local walk-in centre three times over the last month. She has been prescribed antibiotics and salbutamol both of which Amy 'hates'. On examination, she had a dry cough with mild respiratory distress. She has occasional crepitations and widespread wheeze. Parents smoke 'outside the house' but neither has asthma. She is their first child. Clinically, she is well but parents would like to know whether inhalers will help.

\section{INTRODUCTION}

Birth cohort studies have demonstrated that approximately one-third of the children aged between 1 and 5 years suffer recurrent episodes of respiratory symptoms including wheeze. Wheezing prevalence in UK children has increased from twofold to threefold during the past 40 years but may have stabilised or even peaked in the early 1990s. Fortunately, a majority of young children with wheeze tend to have only transient symptoms and do not have subsequently increased risk of asthma or allergy in later life. Nevertheless, childhood wheeze presents a major burden of morbidity during preschool years and there is significant progression from some childhood wheeze to adult asthma. More than $25 \%$ of an unselected birth cohort of children had wheezing that persisted from childhood into adulthood or that relapsed after remission. Despite the relative commonness of childhood wheeze, controversy and confusion exist over which treatments are effective. Doctors and nurses caring for these children face a dilemma regarding the treatment. Although bronchodilators are of clear benefit in older children with asthma, the anatomy and physiology in younger children are significantly different. In this article, we review the known physiology, the current evidence base and offer practical advice for those with a wheezy infant.

\section{SOURCES AND SELECTION CRITERIA}

We searched PubMed and Cochrane databases using the terms 'wheeze' AND 'bronchodilator' OR ' $\beta$-agonist' 'anticholinergic', 'ipratropium', 'adrenaline' or 'salbutamol' limiting the age range to children (or 'preschool children' where available) and selecting what we deemed to be clinically relevant articles. Citation searching of publications identified by database searches identified additional important recent related references. In addition, we drew on our personal archive of references and included pertinent evidence from older children and adults when data are lacking on infants.

\section{THE DIAGNOSIS OF WHEEZE IN CHILDREN}

A wheeze is a continuous high-pitched sound, with musical quality emitting from the chest during expiration. Several studies have shown that parental understanding and use of the word 'wheeze' is often at odds with that of clinicians. ${ }^{5-10}$ Confident retrospective diagnosis of wheezing in a child between wheezy episodes is a clinical challenge. Frequently, parents believe that wheeze is similar to 'gasping', coughing', 'ruttles', 'whistling' or 'rasping', whereas others defined wheeze as a different rate or style of breathing. Even among health professionals, studies have demonstrated interobserver variations of wheeze by stethoscope examination and acoustic analysis. $^{11} 12$ Personal experience has demonstrated that parents can usually give accurate and detailed descriptions of the type of respiratory noises their child makes in between episodes when asked to describe these in detail. However, it is 
vital to ask in detail about any reported respiratory symptoms to maximise diagnostic accuracy when reviewing a child.

\section{PATTERNS OF WHEEZE}

The complete differential diagnosis for wheezing episodes is extensive (box 1). Careful consideration of the pattern and nature of the symptoms including age at onset and variability of symptoms and signs is crucial before any treatment is undertaken; however, a thorough discussion of this is beyond the scope of this article. Once the nature of any respiratory noise has been defined, it is helpful to examine in detail the pattern and periodicity of wheezing episodes.

Current expert opinion suggests that wheeze in preschool children is best divided into two major types, that is, episodic viral wheeze and multiple-trigger wheeze. ${ }^{13}$ This discrimination is mostly of benefit in determining whether inhaled corticosteroids are likely to be of benefit rather than determining whether bronchodilators will be effective. Viral wheeze is defined as wheezing in discrete episodes and the child is well between the episodes. This is usually associated with clinical evidence of viral infection and is the

Box 1 Differential diagnosis of chronic or recurrent wheezing in infancy (modified from 15)

Developmental anomalies

Tracheo-oesophageal fistula and related disorders

Bronchomalacia (localised or generalised)

Stovepipe trachea

Bronchial compression syndromes

Vascular ring

Anomalous origin of the right subclavian artery

Bronchial or pericardial cyst

Congenital heart disease (L-R shunting)

Granuloma or polyps

Host defence defect

Cystic fibrosis

Ciliary dyskinesia

Defects of immunity

Severe combined immune deficiency

Combined IgA and IgG2 deficiency

Postviral syndromes

Recurrent viral infections

Obliterative bronchiolitis

Airway stricture or granuloma or lymphadenitis

Recurrent aspiration

Gastro-oesophageal reflux

Disorders of swallowing

Neuromuscular disease

Mechanical disorders

Perinatal disorders

Chronic lung disease of prematurity

Congenital infection most common phenotype in preschool children. The first episode is frequently diagnosed as bronchiolitis infection. The common microbes identified are respiratory syncytial virus, adenovirus, rhinovirus, para influenza virus and human metapneumovirus. ${ }^{14}$ Episodic viral wheeze commonly should decline over time and disappear by 6 years of age. In contrast, multiple-trigger wheeze has not only discrete wheezing episodes but also symptoms between the episodes and is more likely to persist. ${ }^{15}$

\section{LUNG DEVELOPMENT AND ANATOMY IN EARLY HUMAN LIFE}

Lung development and physiology during fetal and early life have been extensively studied. Despite these studies, some important fallacies still persist among doctors and students alike, most notably a presumed lack of bronchial smooth muscle during early life. Lung development in the human fetus is divided into four overlapping stages after the initial embryonic stage (0-7 weeks) as pseudo-glandular stage (7-17 weeks), canalicular stage (16-26 weeks), saccular stage (24-36 weeks) and alveolar stage (36 weeks to term). ${ }^{16}$ Airway smooth muscle is clearly present from 8 weeks' gestation when desmin is expressed. ${ }^{16} 17$ By 16 weeks, maturation of the innervation is advanced with two major nerve trunks running the entire length of the bronchial tree. $\beta 1$ and $\beta 2$ receptors are known to be present all through the fetal airway including small airways. An extensive and intricate varicose network of bronchial smooth muscle with functional nerve fibres persists throughout infancy and then into adult life. ${ }^{18}$ The presumption that bronchial smooth muscle is lacking during infancy, therefore, seems to owe its origin to clinical studies wherein bronchodilators were shown to be ineffective, rather than to any anatomical or histological studies.

\section{HISTORY AND PHYSICAL EXAMINATION}

As with any clinical scenario, a good history and a detailed clinical examination are important. There is no evidence regarding the usefulness of physical examination between episodes of wheeze in children under 2 years of age. Work of breathing can crudely and indirectly indicate degree of airway narrowing. The presence or absence of wheezing is frequently used in clinical severity scores of younger children. This sign must be interpreted with caution as reductions in airflow associated with increasing airway obstruction may result in a reduction in audible wheeze. Identification of unusual or atypical features may suggest another underlying condition (box 1).

\section{LUNG FUNCTION TESTS AND INVESTIGATIONS FOR WHEEZE}

There is no evidence that chest radiographs help in the diagnosis or management of preschool children with wheeze. ${ }^{19}$ In most young infants, airway calibre 
is likely to be the most important determinant of wheeze. $^{20}$ Infants (8-20 months) with recurrent wheeze are shown to have reduced airway function when compared with healthy controls. ${ }^{21}$ Reduced airway function when present in early infancy was associated with persistent wheeze at 11 years of age, and this relationship was found to be independent of the effect of increased airway resistance and atopy in childhood. ${ }^{22}$ Although there has been an increase in the number of different methods to measure lung function in young children by forced expiratory flows, including thoracic compression technique, ${ }^{23}$ tidal breath analysis, ${ }^{24}$ interrupter resistance measurements, ${ }^{25}$ multiple-breath gas washout and lung volumes, ${ }^{26}$ exhaled nitric oxide, ${ }^{27}$ analysis of induced sputum $^{28}$ and airway hyperresponsiveness, ${ }^{29}$ this has not been of clinical use because of an uncooperative age group. Currently, there are no investigations that are proven to help with the diagnosis or management of wheeze in children under 2 years.

\section{BRONCHODILATORS FOR THE MANAGEMENT OF THE ACUTE WHEEZY EPISODE}

\section{Salbutamol}

Despite a paucity of evidence, salbutamol is commonly prescribed for wheezing episodes in young children. The pharmacology and pharmacokinetics of salbutamol have been relatively well documented in older children and adults. ${ }^{30}$ In older children with asthma, inhaled salbutamol acts rapidly with effects seen within a few minutes having maximal effectiveness $10-15 \mathrm{~min}$ after administration. The half-life of salbutamol in adults is between 2 and $4 \mathrm{~h}$ and it has been proposed that this is similar during childhood. ${ }^{\mathrm{w} 1}$ Salbutamol is a partial agonist, which reaches its maximal bronchodilating effects at relatively low doses. ${ }^{\mathrm{w} 2}$ The results from clinical studies are best described as 'mixed'. Although some studies show a beneficial effect of short-acting $\beta 2$-receptor agonists on lung function and clinical parameters, ${ }^{\text {w2-w4 }}$ some show negligible effects ${ }^{\mathrm{w} 5-\mathrm{w} 8}$ and others demonstrate a worsening of symptoms and/or lung function parameters. ${ }^{\text {w9-w12 }}$ A Cochrane review conducted in 2002 concluded that there is no clear evidence to support the use of $\beta 2$-receptor agonists for recurrent wheeze in children under 2 years. ${ }^{\text {w13 }}$ This review included eight trials and compared the effect of $\beta 2$-agonist against placebo in 229 patients less than 2 years of age in four different settings. Importantly, salbutamol did not have an impact on requirement for hospital admission or length of hospital stay. The evidence, or rather lack of it, is even more compelling for infants with bronchiolitis. A Cochrane review analysed 28 trials with 1912 children with bronchiolitis who were given either bronchodilators or placebo and found no significant improvement in measures of oxygenation, rate of hospitalisation or duration of hospitalisation. ${ }^{\mathrm{w} 14}$

\section{Ipratropium bromide}

The use of anticholinergics to treat infant wheeze also remains controversial. Anticholinergics seem to be biologically active and have effects on symptoms which parents can perceive in the home setting. ${ }^{\text {w15 }}$ However, these data need to be interpreted with caution. In this small study involving just 23 infants, parents reported subjective superiority to nebulised water (OR $0.15,95 \%$ CI 0.04 to 0.64 ), which was not replicated in diary symptom cards (OR 0.60, 95\% CI 0.19 to 1.88). The assumption that nebulised water is biologically inert is in itself questionable. The inhalation of hypotonic solutions may well adversely influence both pulmonary haemodynamics and airway function. The most recent Cochrane review on this area was conducted in 2005 and included this study and five others. Data were included from a total of 321 infants in three different settings. ${ }^{\text {w16 }}$ There were no significant differences in the length of hospital stay between ipratropium bromide and placebo; or between ipratropium bromide and $\beta 2$-agonist compared with $\beta 2$-agonist alone. Although combined ipratropium bromide and $\beta 2$-agonist when compared with $\beta 2$-agonist alone showed reduced need for physician determined 'additional therapy' at $45 \mathrm{~min}$, there were no differences in hospitalisation, respiratory rate or oxygen saturations in emergency department. In fact, the only evidence that anticholinergics have any beneficial clinically relevant measurable effects in the hospital setting comes from a single study. ${ }^{\text {w17 }}$ The quality of this study is rather low (Jadad score 2). While the authors demonstrated an improvement in clinical severity score in children receiving fenoterol and ipratropium in combination compared with nebulised saline at $24 \mathrm{~h}$ (OR $0.06,95 \%$ CI $0.01 \%$ to $0.23 \%$ ), they were unable to show other benefits such as a reduction in hospital stay. Moreover, children in this study who received ipratropium and fenoterol showed a non-significant unexplained increase in hospital stay compared with those who received fenoterol alone (mean difference 0.80 days, $95 \% \mathrm{CI}-0.02 \%$ to $1.62 \%$ ). The authors of the Cochrane review very reasonably conclude that a widespread indiscriminate use of anticholinergic agents in the treatment of wheeze cannot be supported in children under the age of 2 years. ${ }^{\text {w16 }}$ Despite this, the authors' experience is that the use of ipratropium bromide remains pervasive in clinical practice within the UK. Certainly, we would agree with Everard $e t a l^{\mathrm{w} 16}$ in calling for more carefully conducted research in this area.

\section{Epinephrine}

Epinephrine (adrenaline) is a non-selective $\beta$-agonist with a short half-life and a rapid onset of action. Its lack of selectivity may be of use in the treatment of viral bronchiolitis. While the Cochrane review by Gadomski and Brower demonstrated that bronchodilators other than epinephrine are relatively ineffective in 
the treatment of acute bronchiolitis, ${ }^{\mathrm{w} 14}$ but the same is not true of epinephrine. Epinephrine has an additional theoretical benefit because it contains $\alpha$-adrenergic properties in addition to the $\beta$-adrenergic effect. It has been proposed that this additional $\alpha$ adrenergic effect may reduce mucosal oedema and therefore improve clinical status during bronchiolitis. ${ }^{\text {w17 }}$ A 2011 Cochrane review of epinephrine in the treatment of viral bronchiolitis in acute care settings identified 19 studies involving 2256 children. When comparing epinephrine with placebo, no differences were found for length of hospital stay, but there was evidence suggesting that epinephrine is effective for reducing hospital admissions (risk ratio $0.67 ; 95 \%$ CI $0.50 \%$ to $0.89 \%) .{ }^{\text {w18 }}$ When used in combination with dexamethasone, these effects are even more impressive. Results from one large, high-quality trial suggest that combined treatment with systemic glucocorticoids (dexamethasone) and epinephrine may significantly reduce admissions. ${ }^{\text {w19 }}$ However, there is insufficient evidence to support the use of epinephrine for the treatment of bronchiolitis among children already admitted to the hospital. There are no good-quality studies comparing effects of salbutamol, ipratropium and epinephrine in children less than 2 years with wheeze. A study to assess medication for wheeze in 1-5-year-old children in the community (4227 children) showed overtreatment of mild and episodic viral wheeze and chronic cough. ${ }^{\mathrm{w} 20}$ Personal experience of the authors suggests that there is an overuse of inhalers, particularly ipratropium, in preschool children.

\section{LONG-TERM MANAGEMENT AND OUTCOME OF WHEEZE}

Approximately $25 \%$ of the children with persistent asthma had started to wheeze by 6 months and $75 \%$ had wheezing by 3 years in long-term studies. ${ }^{\text {w21-w23 }}$ Rhinovirus and respiratory syncytial virus have been linked to an increased risk of wheezing over time. ${ }^{\text {w24-w26 }}$ In those children with severe early wheeze, half of the hospitalised children under 2 years were symptom free by 5 years and $70 \%$ by 10 years. Probably, due to tendency of relapse in adolescent years, this had decreased to $57 \%$ by $17-20$ years. $^{\text {w27-w29 }}$ These studies also showed that female sex, passive smoking during infancy and early sensitisations to allergens were risk factors for symptoms continuing into adulthood. Young children with severe wheeze have a higher risk of developing asthma later in life particularly if they are also atopic. Parental education regarding avoidance of household smoking and known allergens have shown to be effective in long-term management of wheeze. ${ }^{\text {w30 }}$

\section{DRUG DELIVERY DEVICES}

The selection before prescribing an aerosol device for a child can be confusing due to the availability of many different types. ${ }^{\text {w31 }}$ As a general principle, pressurised metered-dose inhaler (pMDI) plus spacer and nebulisers are the two commonly used devices in wheeze. MDI without spacers are difficult to use in preschool children because of the difficulty in coordinating the device with inspiration. While a few children under 3 years of age can manage MDI plus spacer, most of them will require a face mask. ${ }^{\text {w32 }}$ A systematic study in children less than 5 years of age with acute wheeze or asthma showed that the delivery of inhaled $\beta 2$-agonists by pMDI without spacer was more effective, recovery was quicker and hospital admission was reduced by $60 \%$ when compared with nebulizer. ${ }^{\text {w33 }}$ Parental education in maintaining the equipment and administering the medication is important. The new unwashed and unprimed plastic spacers are electrostatistically charged leading to reduced drug delivery but this can be easily overcome by washing the spacer with detergent and allowing to drip dry. The authors have experienced situations where the wheezy children do not tolerate either of these methods and nurses and parents struggle to deliver the medication. In some of these children, we have used a nebuliser to deliver the medication while monitoring their response closely.

\section{DISCUSSION}

Let us start our summary by returning to the clinical case (Amy) and our own clinical experiences. The authors have seen dozens of children like Amy admitted to hospital over the last 12 months. Our own experience suggests that a significant minority (if not the majority) will have had clinical trials of bronchodilators despite a lack of clinical evidence for such trials of treatment. Indeed, it is common to be faced with a situation where parents report that these treatments have been effective, but there is little objective evidence supporting this. Ironically, those treatments that are most likely to be effective in the emergency room, such as nebulised epinephrine, are rarely used in routine clinical practice. These clinical scenarios place us directly upon the horns of a dilemma. It is difficult to deny treatments, which parents believe are effective without appearing hard-headed and inflexible. Indeed, parents may request extended stays in hospital or indeed re-admission to continue nebulised treatments that are of limited clinical value. The evidence base where it exists suggests that bronchodilators are of limited value in young children. However, this is not because of a lack of airway smooth muscle that is present early in fetal development. Rather, bronchodilators may paradoxically increase airway obstruction in infancy because under normal circumstances, tonic contraction of smooth muscle holds open the small airways. ${ }^{\text {w10 }}$ Administration of bronchodilators which relaxes smooth muscle may lead to increased airway collapse. Thus, we cannot recommend routine use of bronchodilators in any wheezy infant. Careful reassurance may be all that is required. However, if a trial of 
salbutamol is initiated, we would advise that careful, objective re-evaluation of a child 10-15 min after administration is mandatory, and routine use of bronchodilators should only be continued if and only if objective benefit can be shown. We certainly should discourage routine use of any bronchodilators and only continue use in the case of infants where objective evidence of benefit can be demonstrated.

\section{Case 1}

A 6-month-old boy is brought to see the paediatric ST1 because parents are concerned that he has developed loud noisy breathing after having fever and runny nose for 3 days. He was born at term and is fully immunised. He has not needed antibiotics since birth. There is no family history of atopy. On examination, he appears to be coryzal, well hydrated with mild tachypnoea and oxygen saturations of $96 \%$. He has moderate recession and has bilateral expiratory wheeze on auscultation. He is happy and playing in the waiting area. What is the most appropriate course of action with this patient?

Comments-This child has developed wheeze probably secondary to viral upper respiratory tract infection. His wheeze is likely to improve once his viral infection resolves. So his parents were reassured and sent home.

\section{Case 2}

A 20-month-old girl was brought to the emergency department by ambulance from the out of hours $(\mathrm{OOH})$ services. She has been having fever and cough for 2 days, which worsened earlier today. Parents noted that she was working hard and wheezing. They had tried salbutamol inhaler four puffs every $4 \mathrm{~h}$ with no improvement. At $\mathrm{OOH}$, she was given a salbutamol nebuliser and sent by ambulance as her oxygen saturations were $90 \%$ in air. She has been admitted previously with similar history and needed paediatric high dependency unit admission and regular nebulisers. She has eczema and is allergic to eggs. There is a family history of asthma and hay fever. On examination, she has fever $\left(38.2^{\circ} \mathrm{C}\right)$, is tachypnoeic and tachycardic and her saturations are $98 \%$ in $5 \mathrm{l} / \mathrm{min}$ by a face mask. She has widespread wheeze bilaterally on auscultation and has severe recession. What is the most appropriate course of action with this patient?

Comments-This child needs treatment initially with a $2.5 \mathrm{mg}$ salbutamol nebuliser driven by $6 \mathrm{l} / \mathrm{min}$ oxygen and should have continuous monitoring. If there is limited response, then ipratropium bromide may be added to the treatment regimen. An underlying lower respiratory tract infection needs to be considered and antibiotics to be commenced if required. Oral amoxicillin should be used if community-acquired pneumonia is diagnosed on clinical or radiological grounds. Once stabilised, she will need to be admitted for observation and weaning of bronchodilators. She is likely to need follow-up in outpatients.

Collaborators Dr Jyothi Srinivas.

Contributors Both authors contributed equally to this manuscript and act as guarantors for its content.

Competing interests Dr Carroll has received payment for provision of educational material and lecture fees from Takeda, GlaxoSmithKline and Boehringer Ingelheim. Dr Srinivas has no conflict of interests to declare.

Provenance and peer review Commissioned; internally peer reviewed.

\section{REFERENCES}

1 Bisgaard H, Szefer S. Prevalence of asthma-like symptoms in young children. Pediatr Pulmonol 2007;42:723-8.

2 Anderson HR, Gupta R, Strachan DP, et al. 50 years of asthma: UK trends from 1955 to 2004. Thorax 2007;62:85-90.

3 Martinez FD, Wright AL, Taussig LM, et al. Asthma and wheezing in the first six years of life. The Group Health Medical Associates. N Engl J Med 1995;332:133-8.

4 Sears MR, Greene JM, Willan AR, et al. A longitudinal, population-based, cohort study of childhood asthma followed to adulthood. N Engl J Med 2003;349:1414-22.

5 Cane RS, Ranganathan SC, McKenzie SA: What do parents of wheezy children understand by 'wheeze'? Arch Dis Child 2000;82:327-32.

6 Elphick HE, Sherlock P, Foxall G, et al. Survey of respiratory sounds in infants. Arch Dis Child 2001;84:35-9.

7 Mellis C: Respiratory noises: how useful are they clinically? Pediatr Clin North Am 2009;56:1-17.

8 Michel G, Silverman M, Strippoli MP, et al.: Parental understanding of wheeze and its impact on asthma prevalence estimates. Eur Respir J 2006;28:1124-30.

9 Elphick HE, Ritson S, Rodgers H, et al. When a 'wheeze' is not a wheeze: acoustic analysis of breath sounds in infants. Eur Respir J 2000;16:593-7.

10 Turner SW, Craig LC, Harbour PJ, et al. Early rattles, purrs and whistles as predictors of later wheeze. Arch Dis Child 2008;93:701-4.

11 Salgani S, McKenzie ZA, Bush A, et al. A video questionnaire identifies upper airway abnormalities in preschool children with reported wheeze. Arch Dis Child 2005;90:961-4.

12 Elphick HE, Lancaster GA, Solis A, et al. Validity and reliability of acoustic analysis of respiratory sounds in infants. Arch Dis Child 2004;89:1059-64.

13 Brand PLP, Barald E, Bisgaard H, et al. Definition, assessment and treatment of wheezing disorders in preschool children: an evidence-based approach. Eur Respir J 2008;32:1096-110.

14 Papadopoulas NG, Kalaboutsou A. Respiratory viruses in childhood asthma. Curr Opin Allergy Clin Immmunol 2007;7:91-5.

15 Siverman M. Childhood asthma and other wheezing disorders. London, UK: Chapman \& Hall Publication, 1995:381.

16 Jeffery PK. The development of large and small airways. Am J Respir Crit Care Med 1998;157:174-80.

17 Hislop A. Airway and blood vessel interaction during lung development. J Anatomy 2002;201:324-34. 
18 Sparrow MP, Weichselbaum, McCray PB. Development of the innervation and airway smooth muscle in human fetal lung. Am J Respir Cell Mol Biol 1999;20:550-60.

19 Hederos CA, Janson S, Andersson H, et al. Chest X-ray investigation in newly discovered asthma. Pediatr Allergy Immunol 2004;15:163-5.

20 van der Gugten A, Korte K, van der Ent K, et al. Small airway calibre is the most important contributor of wheezing in healthy unselected newborns. Am J Respir Crit Care Med 2011;183:553.

21 Borrego LM, Stocks J, Leira-Pinto P, et al. Lung function and clinical risk factors for asthma in infants and young children with recurrent wheeze. Thorax 2009; 64:203-9.

22 Turner SW, Palmer LJ, Rye PJ, et al. The relationship between infant airway function, childhood airway responsiveness, and asthma. Am J Respir Crit Care Med 2004;169:921-7.

23 LeSouef PN, Hughes DM, Landau LI. Shape of forced expiratory flow volume curves in infants. Am Rev Respir Dis 1988;138:590-7.
24 Haland G, Carlsen KH, Devulapali CS, et al. Lung function development in the first years of life s independent of allergic disease by 2 years. Pediatr Allergy Immunol 2007;18:528-34.

25 Brussee JE, Smit HA, Oopman LP, et al. Interruptor resistance and wheezing phenotypes at 4 years of age. Am J Respir Crit Care Med 2004;169:209-13.

26 Gustafsson P. Inert gas washout in preschool children. Paediatr Respir Rev 2005;6:239-45.

27 Brussee JE, Smit AH, Kerkhoff M, et al. Exhaled nitric oxide in 4 year old children with asthma and atopy. Eur Respir J 2005;35:1180-5.

28 Simpson JL, Wood LG, Gibson PG. Inflammatory mediators in exhaled breath, induced sputum and saliva. Clin Exp Allergy 2005;35:1180-5.

29 Turner SW, Young S, Landau LI, et al. Reduced lung function before and after bronchiolitis and at 11 years. Arch Dis Child 2002;87:417-20.

30 Browne GJ, Wilkins BH. Use of intravenous salbutamol in acute severe asthma. Anaesthesia 2003;58:729-33.

\section{Call for self-assessment questions: Epilogue}

Education and Practice is planning to improve its continuing professional development service to paediatricians. We intend to carry a series of case-based questions in extended matching, multiple-choice or other formats in a new feature called 'Epilogue'.

We invite readers to submit cases accompanied by questions. The text should be no more than 600 words, and might be accompanied by one or two figures, which would include photographs, electrocardiograms, lab results, etc. Real-life cases must have parent/patient consent. Answers should be given, with explanations. Submissions will be peerreviewed and may be altered significantly before publication. Authors will be credited in the journal.

If you want to know more please contact us via archdischild@bmj. com, or to submit a question to http://mc.manuscriptcentral.com/adc and submit under the "Epilogue" category. 